\title{
Performance Evaluation of Scour Protection around a Bridge Pier through Experimental Approach
}

\author{
Rashid FAROOQ, Abdul Razzaq GHUMMAN, Muhammad Atiq Ur Rehman TARIQ*, Afzal AHMED, Abid LATIF, Amjad MASOOD
}

\begin{abstract}
Bridge pier scour threatens the stability of bridges. Several approaches practiced counterbalancing the base of piers from scour, but the use of a collar with protection is considered as effective countermeasure. Present study examines the scour around rectangular cross-sectional pier by applying a rectangular hooked collar, under clear water condition. Various dimensions of hooked collar wall height to hooked collar width $\left(H_{w} / H_{w h}=0.05\right.$ to 0.30$)$ at the bed level are experimentally tested. To quantify the effectiveness of the scour protection, the result of unprotected rectangular pier is referenced. Similar trend is observed in all the side wall height that by changing the wall height from $0.3 W_{p}$ scour starts increasing. Likewise, by reducing the width of the hooked collar up to $1.5 W_{p}$ equilibrium scour depth is observed to be significantly decreased. Further, the laboratory experimental runs showed that width of $1.5 \mathrm{Wp}$ along with side wall height of $0.3 \mathrm{Wp}$ is the most effective dimension for a hooked collar which may be utilized for rectangular unprotected piers. Lastly, the most suitable configuration reduced almost $52.2 \%$ of scouring depth compared to referenced experimental run.
\end{abstract}

Keywords: countermeasure; experimental rectangular flume; hooked collar; pier scouring

\section{INTRODUCTION}

Scouring around bridge piers is a crucial hydraulic engineering problem. It is broadly acknowledged that localized scouring is one of the main causes of bridge collapse apart from structural design issues, inadequate maintenance, and traffic overloading [1-6]. The local scouring of a bridge pier is mainly due to the downwards direction currents at the location of pier front. The scouring mechanism is intensified, and the scouring pit is expanding and wider because of a horseshoe vortex formation at the base of the pier [5, 7-11]. Thus, proper understanding of scouring process and more precise scour depth estimation around pier shape is of utmost significance in Civil engineering.

The shape of the pier is one of the key factors commonly acknowledged as the escalation of the local scour problems to bridges. In the development and consolidation of the vortex formation, the shape of the pier plays a key role [12-14]. In the past, researchers have investigated scouring actions and the flow patterns around circular cross-sectional piers [3, 15-18]. Likewise, numerous scour countermeasures are utilized around cylindrical cross secctional piers to reduce the maximum scour depth. Investigations on piers with circular shapes suggested that collar protection can be effective in controlling local scour [19-25]. Furthermore, Chen et al.; [26] examined the hooked collar performance by analysing multiple positionings of hooked collar at pier and comparing it with pier without any protection. In their research, they utilized a hooked collar having $1.25 \mathrm{~W}$ width, $0.25 \mathrm{~W}$ hook height, and $5 \mathrm{~mm}$ thickness in which $W$ is width of pier. They noticed that it was effective to reduce local scour by placing a hooked collar at channel bed.

Moreover, Farooq and Ghumman [27] conducted clear bed scour experiments to investigate the influence of various geometries of pier on the depth of final scour. They reported that pier with octagonal cross section was observed to be more effective in minimizing local scouring compared to other pier shapes. Recently, Farooq et al. [28] performed experiments to optimize the octagonal hooked collar and assess its efficiency on octagonal cross-sectional pier. A collar with hook provision having width and side wall height of $2.5 W_{p}$ and $0.45 W_{p}$, respectively, was the best in reducing scour depth for octagonal pier shape, where $W_{p}$ is the pier width.

Further, it is noticed from the literature that two pier shapes, such as circular and rectangular, which are often found in concrete and existing steel bridges, are the key subject of previous studies [29-32]. However, as discussed earlier a lot of studies are available in which scour countermeasures were applied around circular piers; contrary, no information of scour countermeasures are observed around rectangular cross sectional piers, except for a few studies of simple collar and riprap countermeasures $[25,33-35]$ based on limited experimental data.

Various researchers have recently examined a new form of collar having provision of hook around circular and octagonal pier shapes $[26,28]$. They concluded that the performance of pier protected with hooked collar is satisfactorily improved in comparison to pier protected with simple collar. Therefore, it is of utmost importance to optimize the dimensions of hooked collar around rectangular cross-sectional piers, based on the optimization procedure recommended by Farooq et al. [28].

\section{MATERIALS AND METHODS \\ 2.1 Experimental Flume}

All the experimental runs are conducted in a leveled flume channel (length $=20 \mathrm{~m}$, width $=1 \mathrm{~m}$, and depth $=$ $0.75 \mathrm{~m}$ ), having a recirculating system. The channel has concrete base, having a straight entrance inlet, and a thickness of $1.2 \mathrm{~cm}$ sidewall glass. The channel is distributed in three parts: inlet, main section, and outlet.The main segment includes uniformly graded layer of sand bed which is 6 meter long and 0.3 meter thick and the pier is centered at the middle of the sediment bed and fixed on the bed of the flume with glue.This segment is used to perform all scour experiments. The bridge pier is positioned in such a manner that the pier's center overlaps the flume's mid-section. A gated weir of rectangular shape is placed towards the outlet segment of the flume, through 
which flow discharge is measured. Fig. 1a, Fig. 1b show a cross sectional and side view sketch of the experimental setup.
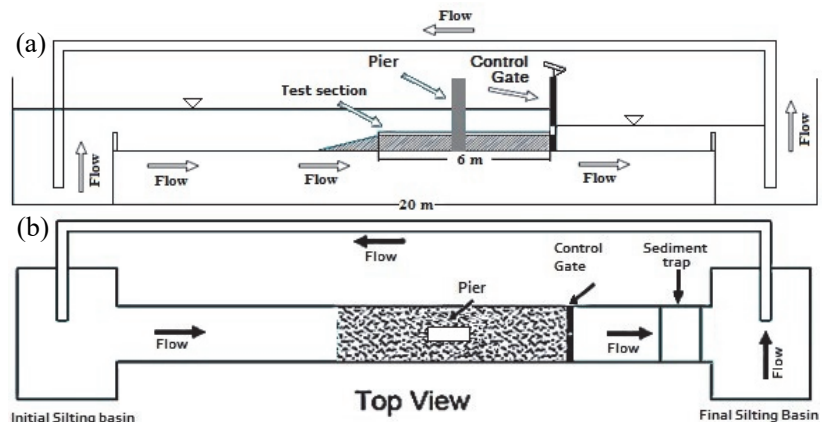

Figure 1 Detail of experimental rectangular flume (a) cross sectional view (b) top view

\subsection{Sediment Bed}

The working section of about $6 \mathrm{~m}$ long is filled at a height of $0.30 \mathrm{~m}$ with sand as can be seen in Fig. 1a. The median sediment grain size $d_{50}=0.91 \mathrm{~mm}$ is used for all the experiments. The sediment size distribution has geometric standard deviation of $\sigma_{g}=\left(d_{84} / d_{16}\right)^{0.5}$, which is $1.20\left(d_{16}\right.$ and $d_{84}$ are the sediment size, for which $16 \%$ and $84 \%$ of the mass of the sediments are finer, respectively). The determined values of geometric standard deviation $\sigma_{g}$ of bed material is smaller than 1.30 , which is usually considered as the uniformly graded sediment's upper limit [33]. Likewise, the friction angles and specific gravity are $\alpha_{s}=30^{\circ}$ and $S_{g}=2.60$ for utilized bed particles, respectively. Since $W_{p} / d_{50}$ is more than $50\left(W_{p} / d_{50}=54.9\right)$, with $W_{p}=5 \mathrm{~cm}$ as the width of pier, the scour hole becomes negligible due to the effect of sediment size [36]

\subsection{Flow Conditions}

The discharge for all experimental runs is adjusted to normalize the shear stress of bed and for the initial particle movement at smooth layer, of median sediment size of $0.91 \mathrm{~mm}$, it must not surpass the critical value. A flow rate of $0.060 \mathrm{~m}^{3} / \mathrm{s}$ is maintained in all performed experiments. In these experiments, the flow depth $d_{f}$ is selected as $17 \mathrm{~cm}$ so that flow shallowness effect can be mitigated i.e., $d_{f} / W_{p}$ $\geq 2.5$ [20]. The Froude number, $\left(F_{r}=U / \sqrt{g d_{f}}\right)$ where ' $U$ ' represents mean approaching velocity of flow, and $g$ is gravitational acceleration, against the corresponding flow discharge is 0.27 . Tab. 1 demonstrates the several parameters of flow related to the experiments.

\begin{tabular}{|c|c|c|c|c|c|c|c|c|}
\hline Table 1 Flow parameters for the sand bed \\
\begin{tabular}{|c|c|c|c|c|c|c|} 
Discharge, / \\
$\mathrm{m}^{3} / \mathrm{s}$
\end{tabular} & $\begin{array}{c}\text { Flow } \\
\text { Depth, } d_{f} / \\
\mathrm{m}\end{array}$ & $\begin{array}{c}\text { Median } \\
\text { Grain Size, } \\
d_{50} / \mathrm{m}\end{array}$ & $\begin{array}{c}\text { Average flow } \\
\text { Velocity, } U_{a v} / \\
\mathrm{m} / \mathrm{s}\end{array}$ & $\begin{array}{c}\text { Critical } \\
\text { Velocity, } U_{c} / \\
\mathrm{m} / \mathrm{s}\end{array}$ & $\begin{array}{c}\text { Shear } \\
\text { Velocity, } U_{*} \\
/ \mathrm{m} / \mathrm{s}\end{array}$ & $\begin{array}{c}\text { Flow } \\
\text { Intensity, } \\
U / U_{c}\end{array}$ & $\begin{array}{c}\text { Critical } \\
\text { Shields } \\
\text { Parameter } \tau^{*}\end{array}$ & $\begin{array}{c}\text { Reynolds } \\
\text { Number, } \\
U d_{f} / v\end{array}$ \\
\hline 0.060 & 0.17 & 0.00091 & 0.35 & 0.39 & 0.022 & 0.90 & 0.035 & $\begin{array}{c}\text { Froude } \\
\text { Number, } F_{r}\end{array}$ \\
\hline
\end{tabular}

The intensity of flow is kept as $\left(U / U_{c}=0.90\right)$ maintining the condition of clear water in specified experimental runs, in which $U_{c}$ and $U$ represent critical value and average flow velocity at which the sediment movement is initiated, respectively. In the current study, the Shields chart is utilized to determine the critical shear velocity $\left(U_{*_{c}}\right)$ for sediment particles, as seen in Tab. 1 . Moreover, in each experiment, the critical flow velocity $U_{c}$ for rough bed materials is computed by logarithmic average velocity equation, as follows [8]:

$$
\frac{U_{c}}{U_{c}^{*}}=5.75 \log \left(\frac{h}{k_{e}}\right)+6
$$

In above equation $h$ is the depth of flow and $k_{e}=2 d_{50}$ is the height of equivalent roughness.

\subsection{Hooked Collar Countermeasure}

Current study aims to investigate rectangular hooked collar, an essential scour countermeasure around a rectangular pier having $5 \mathrm{~cm}$ width. Hooked collar is explored around rectagular pier by changing the dimension of hooked collar wall height $H_{w h}$ along with width $H_{w}$. Hence, a range of combinations with four different widths $\left(H_{w}=1.5 W_{p}, 2 W_{p}, 2.5 W_{p}, 3 W_{p} \mathrm{~cm}\right)$ and three sidewall heights $\left(H_{w h}=0.15 W_{p}, 0.3 W_{p}, 0.45 W_{p} \mathrm{~cm}\right)$ is examined. The hooked collar thickness is adjusted as $5 \mathrm{~mm}$ [28]. Whilst the ratio of flume breadth ' $B$ ' to width of pier, $B / W_{p}$ is 20 , at the contracted cross section no bed degradation is noticed; this agrees well with [37] that reported that contraction scouring effect becomes minimum when $B / W_{p}$ $\geq 10$. Thus, it is concluded for the current study that effect of contraction scour is negligible.

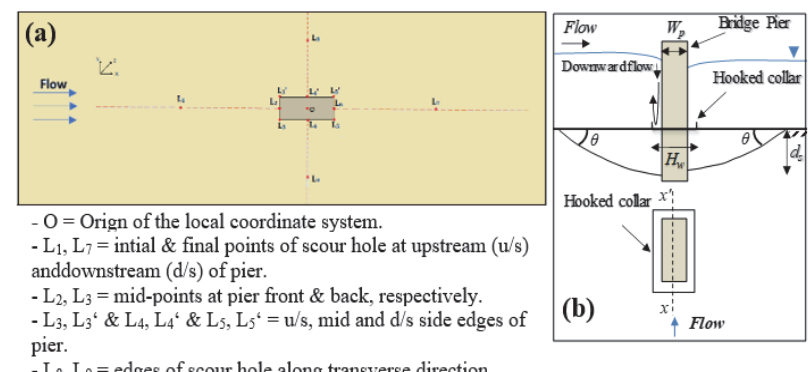

Figure 2 Details of (a) scoured hole measuring points (b) hooked collar around rectangular pier

Fig. 2a, Fig. 2b show the descriptions of points selected to measure the scoured hole including the cross sectional and pier side view protected with hooked provision. Fig. $2 \mathrm{~b}$ presents a schematic of a hooked collar arrangment around pier, whereas Fig. 2a illustrates the location of measuring points of the developed scoured hole, and maximum depth of scour at the bridge pier's front is located at $L_{2}$. Here, coordinates $(x, y, z)$ are streamwise, bottom-normal to the flow and in transverse directions, respectively. The global coordinates origin $(0,0$ and 0$)$ is considered at the middle of pier and at the centerline of the rectangular channel above the sediment bed surface. 


\subsection{Experimental Procedure}

Experiments are performed in two rounds for the assessment of the efficient hooked collar around octagonal pier as best performing dimension: (a) referenced phase and (b) exploratory. An unprotected pier (run 0) and pier protected with collar $C_{\mathrm{o}}$ (run $0^{\prime}$ ) are examined in the initial stage. For the collared pier, the common place practice of placing a collar at bed surface, three times wider than pier width is tested.
In the second stage, the dimension of hook collar sidewall along with width varied and it was analyzed which was the most suitable configuration in shielding the pierbase from local scouring. Therefore, fourteen experimental runs in total are carried out: (a) two in reference stage and (b) twelve in second exploratory stage. In Specific, four runs are carried out for each selected side wall height dimension by increasing collar width to find an optimal rectangular hooked collar configuration.

Table 2 Characteristic control for the hooked collar parameters and generating scouring metrics

\begin{tabular}{|c|c|c|c|c|c|c|}
\hline \multirow{2}{*}{ Run } & \multicolumn{2}{|c|}{ Hooked collar } & \multirow{2}{*}{$H_{w h} / H_{w}$} & $d_{s} / \mathrm{cm}$ & \multirow{2}{*}{$d_{s} / d_{s}{ }^{\prime}$} & \multirow{2}{*}{ Efficiency $\varepsilon / \%$} \\
\cline { 2 - 5 } & Sidewall height $H_{w h} / \mathrm{cm}$ & Width $H_{w} / \mathrm{cm}$ & - & 15.9 & - & 0 \\
\hline 0 & - & - & - & 10.3 & 0.65 & 35.22 \\
\hline $0^{\prime}$ & - & - & - & 8.4 & 0.53 & 47.17 \\
\hline 1 & 0.75 & 10 & 0.08 & 8.6 & 0.54 & 45.91 \\
\hline 2 & 0.75 & 12.5 & 0.06 & 9.0 & 0.57 & 43.40 \\
\hline 3 & 0.75 & 15 & 0.05 & 9.2 & 0.58 & 42.14 \\
\hline 4 & 0.75 & 7.5 & 0.20 & 7.6 & 0.48 & 52.20 \\
\hline 5 & 1.5 & 10 & 0.15 & 7.9 & 0.50 & \\
\hline 6 & 1.5 & 12.5 & 0.12 & 8.2 & 0.52 & \\
\hline 7 & 1.5 & 15 & 0.10 & 8.4 & 0.53 & 48.43 \\
\hline 8 & 1.5 & 7.5 & 0.30 & 8.1 & 0.51 & 47.17 \\
\hline 9 & 2.25 & 10 & 0.23 & 8.5 & 0.53 & 49.06 \\
\hline 10 & 2.25 & 12.5 & 0.18 & 8.9 & 0.56 & 46.54 \\
\hline 11 & 2.25 & 15 & 0.15 & 9.0 & 0.57 & 44.03 \\
\hline 12 & 2.25 & & & 43.40 \\
\hline
\end{tabular}

In both stages, the flow conditions, protocols, and experimental procedure are similar for all runs. For example, from the $10.5 \mathrm{~m}$ of the flume inlet, the pier without protection is vertically aligned on the sediment bed, wherein the bed material is well compacted and the surface of top layer is ensured to level with the corresponding flume bed. The channel is then eventually allowed to start filling with water, so that entrapped air is removed from the sand bed. The scouring mechanism started immediately in the first hour and with the aid of three point gauges, the scouring depth at pier upstream edges $\left(L_{3}, L_{3}^{\prime}\right)$ and more importantly at pier front $\left(L_{2}\right)$ is measured every 12 minutes $(+0.1 \mathrm{~mm}$ accuracy) and from thereafter measuring periods increased.

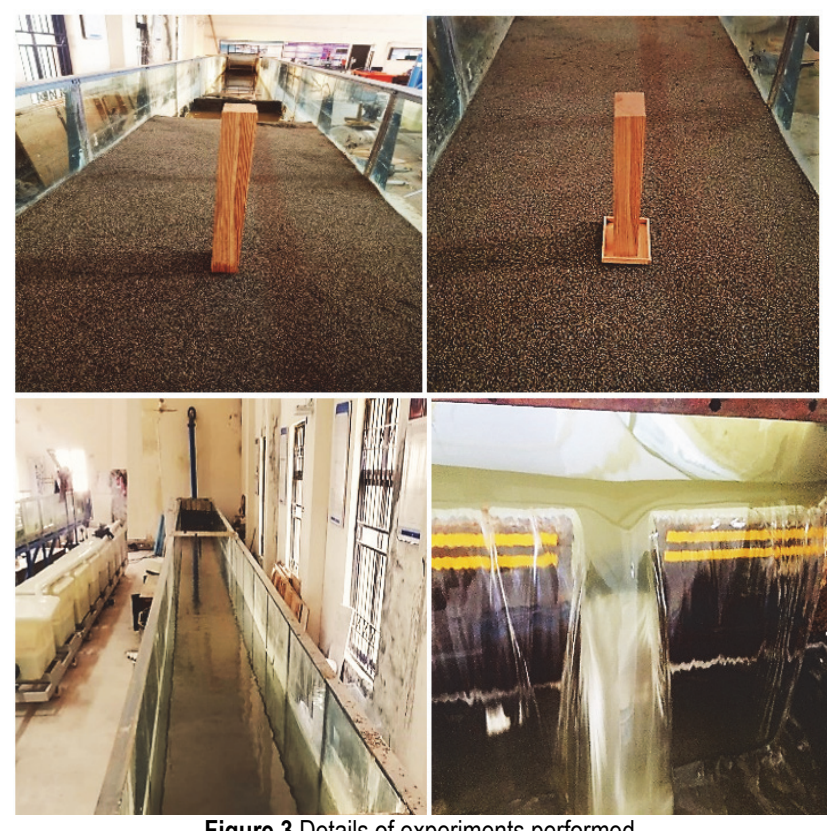

Figure 3 Details of experiments performed
At the end of the test segment, the outlet segment includes the sediment trap tank and outlet pipe. Experiment is halted after 24 hours as the time duration of experiment is approached [36] and water is carefully drained out of the working section to maintain the scour pattern uneffected. By utilizing hook gauge, the scoured depth and its profile across the pier are precisely measured. From the middle of the bridge pier the eroded profile is measured at a diameter of $1.0 \mathrm{~m}$ with pier at the centre (Fig. 2). The details of pier with and without protection in the flow channel are shown in Fig. 3.

\section{RESULTS AND DISCUSSION}

\subsection{Scouring Depth Development}

A significant parameter that is highly crucial for the structural design of bridge piers is the final depth of scour in proximity of a scour countermeasure. Moreover, for the interpretation of scour systems dynamics and of the variables attributable to geometrical and hydraulic configurations, the time evolution is of key significance. The intensity of flow and ratio of obstruction have also a major impact on the final scoured depth as reported by Pagliara and Carnacina [38, 39]. Furthermore, in the current study, the time development of scoured depth at final scoured depth location for unprotected pier and pier with simple collar protected and hooked collar with the similar conditions of flow, can be observed in Fig. 4. The scouring hole depth gradually progresses for the pier without any protection and approaches to a maximal depth and then asymptotically reaches a normal state as reported by [28]. Thus, it may also be mentioned that the rise in the depth of scour decreases temporally. The observed evidence shows that during the initial 5 hours of the experimental run, almost $40 \%$ of final depth of scouring for best hooked collar configuration (run 5) is reached, which for the case of unprotected pier (run 0 ) is $70 \%$. 


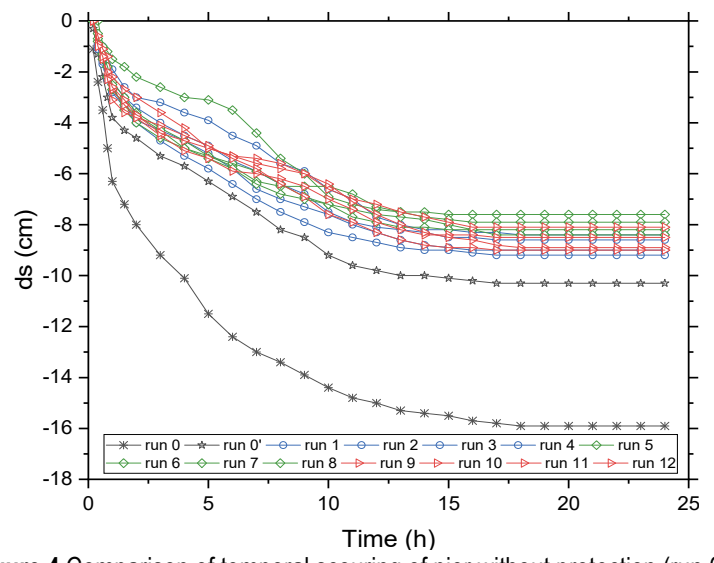

Figure 4 Comparison of temporal scouring of pier without protection (run 0 ), collared protected (run 0') and hooked collar protected (run 1 - 12) pier

The maximum scouring is first observed at the sides of pier and afterwards shifted towards the upstream side of the pier specifically at the pier front in all cases, when the pier is unprotected and protected. Fig. 4 shows the temporal development comparison of the scouring depth between unprotected and protected pier. It can clearly be observed that in all experimental runs with rectangular hooked collar the scour depth initiates with delay mainly because of the provision of hook which probably diminishes the initial impact of downward flow at the upstream of the pier thereby weakening the development of the horse show vortex. Further, this initial delay further increased as the width of the hooked collar reduced and the rate of scour depth development reduced compared to collared and unprotected pier. Likewise, for the collared pier the rate of scour was delayed for short duration and then accelerated until reaching the final scour depth.

\subsection{Maximum Scour Depth}

The maximum scoured depth variation of pier with and without protection is reported in Fig. 5. The findings reveal that the maximum scoured depth $d_{s m}$ has been substantially decreased with the addition of hooked collar provision. For instance, in the scenario where a hooked collar pier is provided, the reduction is more evident relative to a collar protected pier. In comparison, the decrease in the performance for the collared pier and the optimal hooked collar dimensions are $35.22 \%$ and $52.20 \%$, relative to the pier without protection.

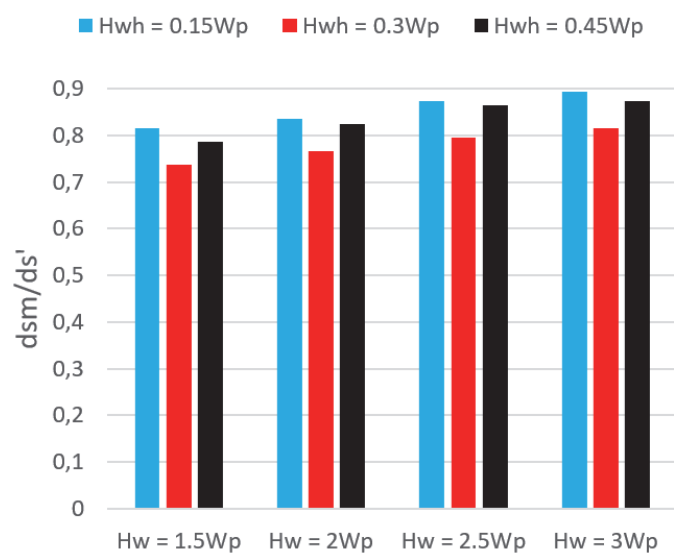

Figure 5 Comaprison of final scour depth of rectangular hooked collar dimensions with respect to collared pier
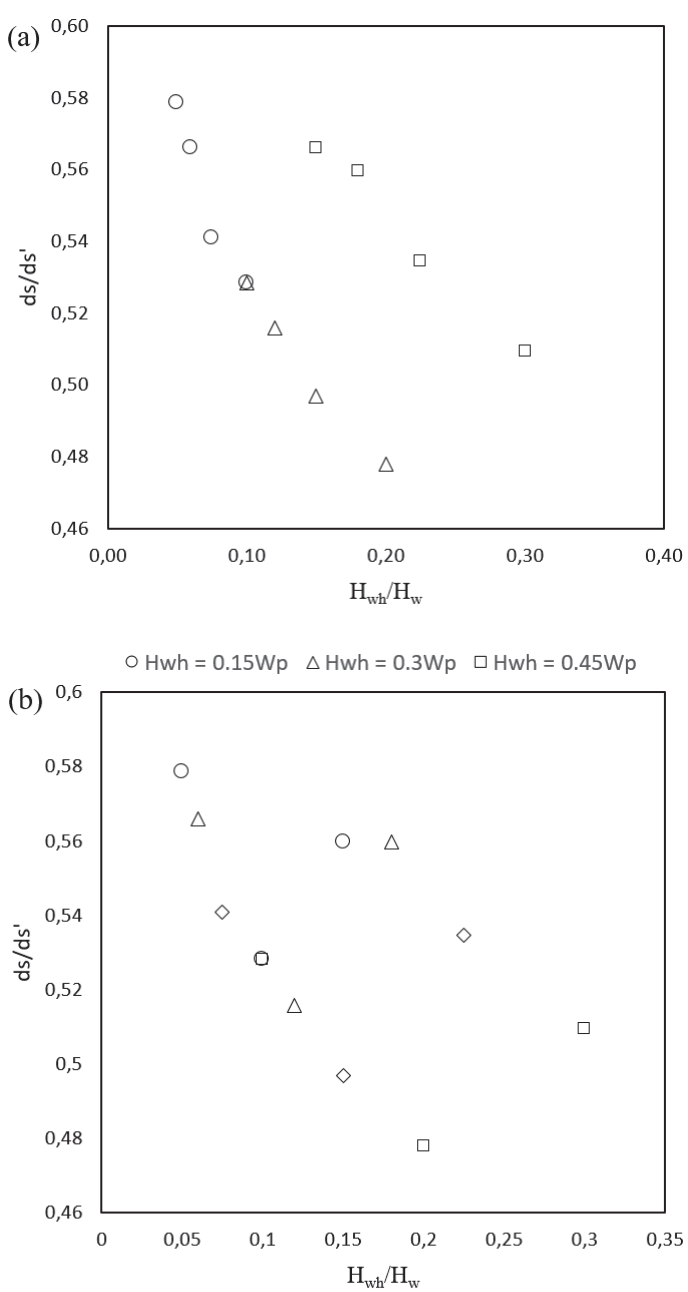

$\square \mathrm{Hw}=1.5 \mathrm{Wp} \diamond \mathrm{Hw}=2 \mathrm{Wp} \Delta \mathrm{Hw}=2.5 \mathrm{Wp} \circ \mathrm{Hw}=3 \mathrm{Wp}$

Figure 6 Effects of various combinations of hooked collar configurations at bed level

\subsection{Rectangular Hooked Collar Assessment}

Four different widths $(7.5,10,12.5$ and $15 \mathrm{~cm})$ along with the three sidewall heights $(0.75,1.5$ and $2.25 \mathrm{~cm})$ of rectangular hooked collar are explored around the rectangular pier shape. Hence, a long duration of 12 experimental runs corresponding to collar with hook protection are performed. Fig. 6 shows a comprehensive summary of hooked collar results, for example, four different heights of the sidewall and three widths of hooked collar are varied when it is fixed around pier at bed surface. Interestingly, it is noted that by testing each dimension of hooked collar width (run 1 - 4) for the smallest sidewall height (i.e., $0.15 W_{p}$ ), the final scouring depth for the smallest dimension of hooked collar width reduced significantly at the upstream of pier. Consequently, this observation was the same for all other cases, as wall height dimension of hooked collar increased against various widths.

Likewise, the process of scour enhancement is also observed as the hooked collar sidewall height increases or decreases from $0.3 W_{p}$ (run 5, $6 \& 11$ ); after this dimension the scouring hole starts scaling up its depth. More specifically, this trend can be observed in run $1,5 \& 9$, run $2,6 \& 10$, run $3,7 \& 11$ and run $4,8 \& 12$. Certainly, the key explanation for this increment in scouring depth is 
possibly that after $0.3 W_{p}$, the rectangular sidewall height (i.e., $0.15 W_{p}$ ) is too small to tackle the generation of the horseshow vortex due to the downflow at pier front and similarly for larger dimension of sidewall height (i.e., $\left.0.45 W_{p}\right)$ the approaching water observes a large obstruction and thus downward flow initiates at sidewall front, generating vortex development. Indeed, the $0.3 W_{p}$ sidewall height is the most effective and efficient dimension to reduce the maximum depth of scouring. Thus, the hooked collar when fitted at bed level with sidewall height $0.3 W_{p}$ and width $1.5 W_{p}$ is observed to be the optimum configuration for rectangular hooked collar.

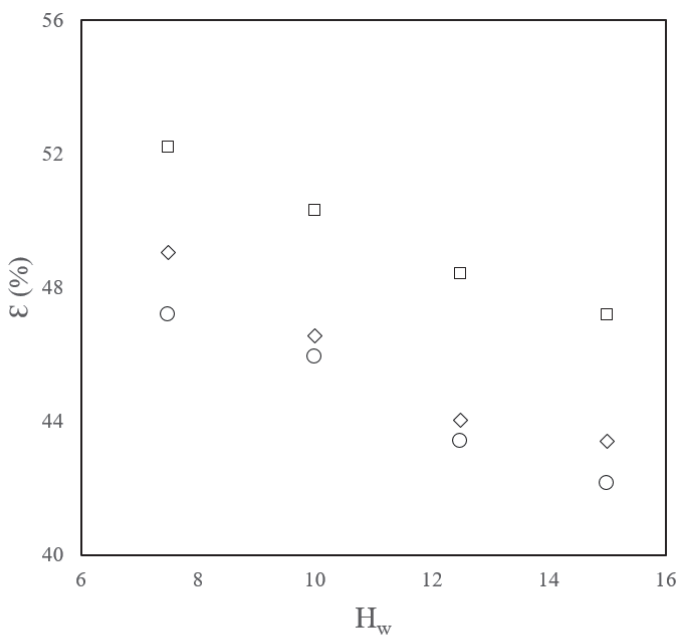

O Hwh $=0.15 \mathrm{Wp} \quad \square \mathrm{Hwh}=0.3 \mathrm{Wp} \quad \diamond \mathrm{Hwh}=0.45 \mathrm{Wp}$

Figure 7 Efficiency $E$ versus $H_{d}$ and $H_{w h}$ attained with different hooked collar provisions

Moreover, for scour depth percent reduction $\varepsilon(\%)$, the efficiency of the suggested scour countermeasure for pier is computed at the upstream base as specified below:

$\varepsilon(\%)=\left(d_{p}-d_{h}\right) / d_{u p} \times 100$

In Eq. (2), $d_{p}$ and $d_{h}$ represent final equilibrium scouring depth computed at rectangular pier without protection and pier with the hooked collar protection, respectively.

It is further observed that by varying the width of the hooked collar for three different sidewall heights (i.e., $0.15 W_{p}, 0.3 W_{p} \& 0.45 W_{p}$ ) seperately, the runs $1,6 \& 11$ are the most efficient and runs $4,9 \& 14$ are the most inefficient dimensions for each sidewall height selection, reducing the scour depth in comaprison to unprotected pier (run 0 ) $47.17 \%, 52.20 \% \& 49.06 \%$ and $42.14 \%, 47.17 \%$ \& $43.40 \%$, respectively. From Fig. 7, the maximal percent reduction of $52.20 \%$ for the hooked collar configuration (run 5) is noted when the width of $1.5 W_{p}$ and sidewall height of $0.3 W_{p}$ are applied compared to rectangular pier without protection (run 0 ). Likewise, the effectiveness of the collared pier is also observed and it is noted that provision of collar is $35.22 \%$ effective compared to unprotected pier. Interestingly, if the collared pier is compared with the most suitable dimension of hooked collar (run 5) for rectangular pier, the effectiveness of hooked collar in terms of scour reduction is $26.21 \%$.

\subsection{Scour Hole Profile}

Fig. 8 shows the longitudinal profiles of the scoured hole pattern observed at the location of the maximum depth of scouring plotted for the unprotected and protected pier. It can be seen that the longitudinal profiles of various hooked collar dimensions show interesting scour patterns with different upstream and downstream profiles, in comparison with collared and unprotected pier, under the same flow conditions. It can be seen that maximum length of scour section along the longitudinal direction is monitored for the experimental run 4 mainly because it has the maximum depth of scour hole compared to other hooked collar cases.
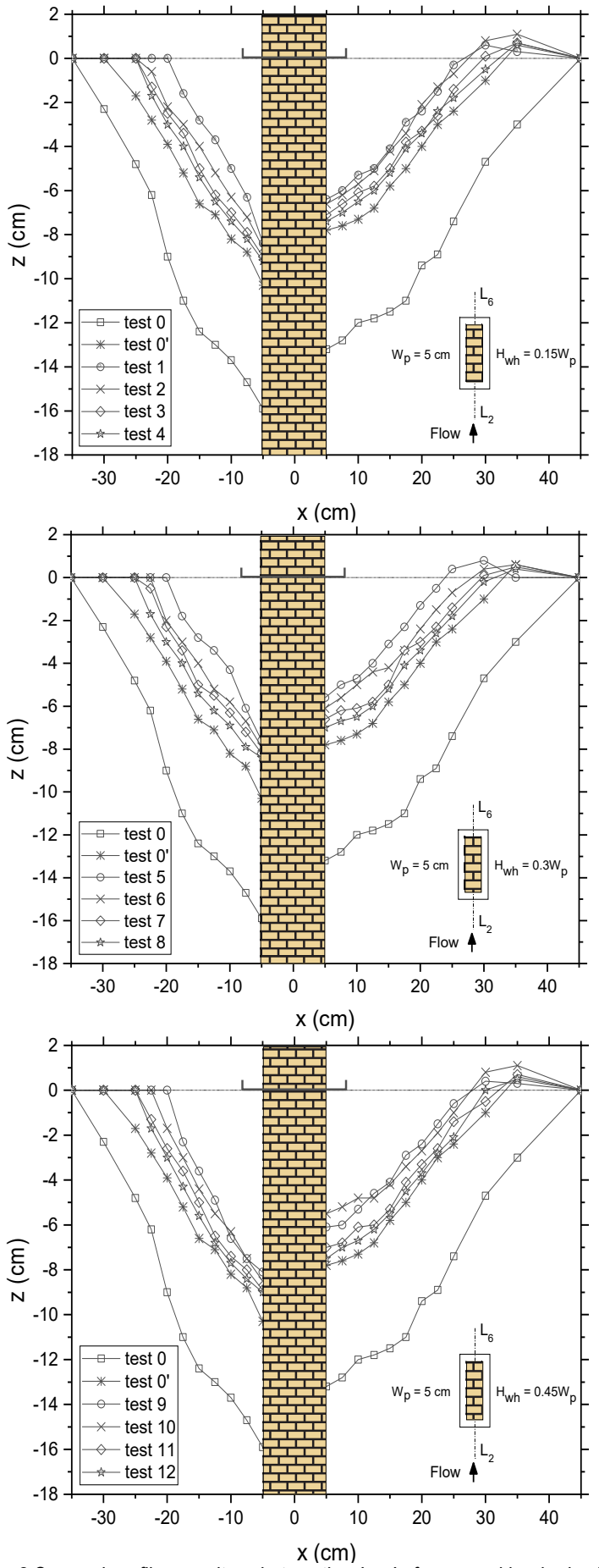

Figure 8 Scoured profiles monitored at section $L_{2}-L_{6}$ for several hooked collar configurations, pier protected with collar and simple rectangular pier 
Likewise, the run with minimum scour hole depth is observed to have smaller streamwise scoured length. Also, the effect of reducing width of the hooked collar resulted in the decrease of scour section length in longitudinal direction. This decline is particularly more influential when the sidewall height remains $0.3 W_{p}$ for the hooked collar pier.

As can be seen in Fig. 8, the upstream side slope of the scoured hole in every experimental run is smaller than downstream side and is near to the repose angle of sediment material $\left(\alpha_{s}=32^{\circ}\right)$. Furthermore, for the scoured hole at pier front, the bed slopes are almost identical for all profiles of various combinations of hooked collar runs [28]. It can also be seen that the largest deposition pockets of sediment are at the pier downstream.

\subsection{Scour Hole Volume}

The scour hole volume $V_{s}$, which indicates the loss of soil amount at the pier base, is computed for all experimental runs by applying Simpson rule of $3 / 8^{\text {th }}$ from the scoured contoured maps. In general, $V_{s}$ progress is observed when the width of hooked collar around the rectangular pier against all sidewall dimensions is maximum to the condition, when the width of the hooked collar for all sidewall dimensions is the smallest. The measurement of $V_{s}$ is noted lowest at $0.012 \mathrm{~m}^{3}$ for the optimal configuration of $H_{w}$ and $H_{w h}$. This result indicates a reduction of $77.2 \%$ in scour hole volume and for maximum scour depth $d_{s m}$ is $52.2 \%$ compared to unprotected pier.

The overall scour hole volume $V_{s}$, is also supposed to decline with maximum scour depth as the scour depth extent along streamwise is reduced with $d_{s}$. An equation fitted with the data established, as shown in Fig. 9, precisely shows the characterization of the relationship between ds and $V_{s}$. Studying the equation $V_{s}=2.1 d_{s}^{2}, V_{s}$ and $d_{s}$ are respectively in cubic meters and meters, scour volume is observed to decline quadratically with $d_{s}$.

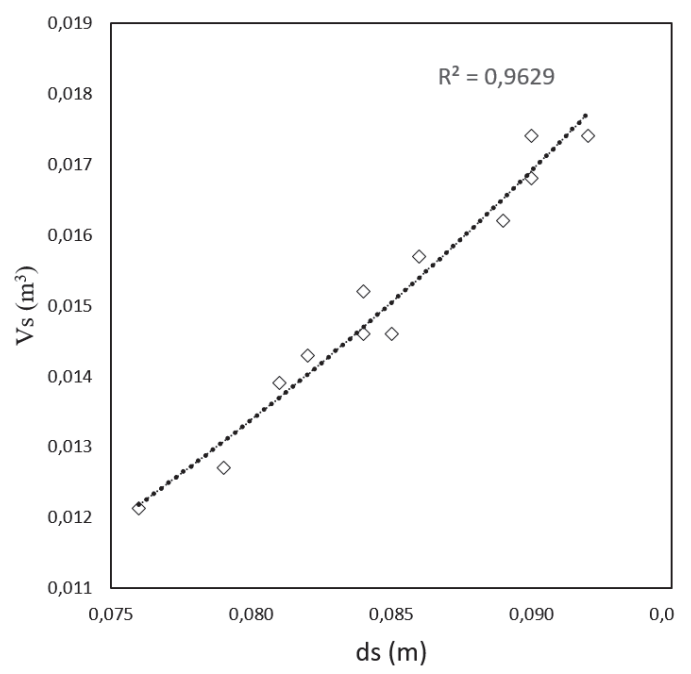

Figure 9 Scour hole volume computed in the vicinity of hooked collar pier. Dash line curve is a quadratic curve $\left(V_{s}=2.1 d_{s}^{2}\right)$ fitted over the data

The equation is similar to the one suggested by Ebrahimi et al. [29], that is, $V_{s}=2.2 d_{s}^{2}$, in which $V_{s}$ and $d_{s}$ are in cubic meters and centimeters, respectively, in the presence of debris for a sharp nose pier. This data may be helpful for post-flood remediation preparation [40], where the final depth of scouring is usually calculated initially.

\section{CONCLUSION}

Current study presents thorough hydraulic experiments investigating the best rectangular hooked collar dimension in terms of reducing local scour with unprotected and protected collared pier as reference. The main conclusions from this research are as follows:

1) It is important to recommend a rectangular hooked collar which may help to generalize the optimal configuration to other dimensions for such type of pier shapes. First, it is concluded that increasing collar width beyond $1.5 W_{p}$ is not effective and economical since scour depth starts increasing and scour hole volume expands, thereby exposing pier foundation more drastically compared to other dimensions. Second, by varying the hooked collar height along with hooked collar width, it is noticed that by increasing or decreasing its dimension from $0.3 W_{p}$ may result in scour increament thereby enhancing the scour mechanism.

2) The most effective hooked collar dimension to protect pier against local scouring is when the width of $1.5 W_{p}$ and sidewall height of $0.3 W_{p}$ is applied around rectangular cross sectional pier. In comparison with rectangular pier without protection, its reduction percentage is $52.2 \%$.

3) Scour countermeasure is an important parameter in reducing scouring process. Current investigation proposed a rectangular hooked collar around rectangular crosssectional pier as the most suitable pier modification countermeasure.

4) The proposed equation for scour hole volume may be effective for estimating the sediment material volume around rectangular cross sectional piers necessary to fill scoured hole in remediable filed work for post-floods calculated.

\section{Acknowledgements}

The authors are thankful to the anonymous reviewers of this paper.

\section{REFERENCES}

[1] Singh, N. B., Devi, T. T., \& Kumar, B. (2020). The local scour around bridge piers a review of remedial techniques. ISH Journal of Hydraulic Engineering, 00(00), 1-14. https://doi.org/10.1080/09715010.2020.1752830

[2] Khosronejad, A., Kang, S., \& Sotiropoulos, F. (2012). Experimental and computational investigation of local scour around bridge piers. Advances in Water Resources, 37, 7385. https://doi.org/10.1016/j.advwatres.2011.09.013

[3] Manes, C. \& Brocchini, M. (2015). Local scour around structures and the phenomenology of turbulence. Journal of Fluid Mechanics, 779, 309-324. https://doi.org/DOI: 10.1017/jfm.2015.389

[4] Pandey, M., Chen, S. C., Sharma, P. K., Ojha, C. S. P., \& Kumar, V. (2019). Local Scour of Armor Layer Processes around the Circular Pier in Non-Uniform Gravel Bed. Water, 11(7), 1421. https://doi.org/10.3390/w11071421

[5] Pagliara, S., Palermo, M., \& Azizi, R. (2015). Scour control at bridge piers using macro-roughness elements. Proceedings of the Institution of Civil Engineers: Water 
Management, 168(4), 174-188. https://doi.org/10.1680/wama.14.00006

[6] Xianbin, H., Chenyang, L., Song, H., Chunyang, C., Yujiao, M., Bo, L., \& Yong, H. (2019). An evaluation on bridge bearing capacity under scour and re-occurrence of strong earthquake. Tehnicki Vjesnik, 26(3), 807-814. https://doi.org/10.17559/TV-20170717105559

[7] Kumar, V., Raju, K. G. R., \& Vittal, N. (1999). Reduction of local scour around bridge piers using slots and collars. Journal of Hydraulic Engineering, 125(12), 1302-1305. https://doi.org/10.1061/(ASCE)0733-9429(1999)125:12(1302)

[8] Lauchlan, C. S. \& Melville, B. W. (2001). Riprap protection at bridge piers. Journal of Hydraulic Engineering, 127(5), 412-418. https://doi.org/10.1061/(ASCE)0733-9429(2001)127:5(412)

[9] Tafarojnoruz, A., Gaudio, R., \& Dey, S. (2010). Flowaltering countermeasures against scour at bridge piers: A review. Journal of Hydraulic Research, 48(4), 441-452. https://doi.org/10.1080/00221686.2010.491645

[10] Vijayasree, B. A., Eldho, T. I., Mazumder, B. S., \& Ahmad, N. (2019). Influence of bridge pier shape on flow field and scour geometry. International Journal of River Basin Management, 17(1), 109-129. https://doi.org/10.1080/15715124.2017.1394315

[11] Guan, D., Chiew, Y., Wei, M., \& Hsieh, S. (2019) Characterization of horseshoe vortex in a developing scour hole at a cylindrical bridge pier Characterization of horseshoe vortex in a developing scour hole at a cylindrical bridge pier. International Journal of Sediment Research 34(2), 118-124. https://doi.org/10.1016/j.jjsrc.2018.07.001

[12] Farooq, R., Ghumman, A. R., \& Hashmi, H. N. (2017). Influence of Pier Modification Techniques for Reducing Scour around Bridge Piers. World Academy of Science, Engineering and Technology, International Journal of Civil, Environmental, Structural, Construction and Architectural Engineering, 11(4), 462-468.

[13] Yanmaz, A. M. \& Üstün, I. (2001). Generalized reliability model for local scour around bridge piers of various shapes. Turkish Journal of Engineering and Environmental Sciences, 25(6), 687-698.

[14] Vijayasree, B. A., Eldho, T. I., \& Mazumder, B. S. (2019). Turbulence statistics of flow causing scour around circular and oblong piers. Journal of Hydraulic Research, 1686. https://doi.org/10.1080/00221686.2019.1661292

[15] Apsilidis, N., Diplas, P., Dancey, C. L., \& Bouratsis, P. (2015). Time-resolved flow dynamics and Reynolds number effects at a wall-cylinder junction. Journal of Fluid Mechanics, 776, 475-511. https://doi.org/10.1017/jfm.2015.341

[16] Chen, Q., Qi, M., Zhong, Q., \& Li, D. (2017). Experimental study on the multimodal dynamics of the turbulent horseshoe vortex system around a circular cylinder. Physics of Fluids, 29(1), 15106. https://doi.org/10.1063/1.4974523

[17] Fael, C., Lança, R., \& Cardoso, A. (2016). Effect of pier shape and pier alignment on the equilibrium scour depth at single piers. International Journal of Sediment Research, 31(3), 244-250. https://doi.org/10.1016/j.jisrc.2016.04.001

[18] Yao, W., An, H., Draper, S., Cheng, L., \& Harris, J. M. (2018). Experimental investigation of local scour around submerged piles in steady current. Coastal Engineering, 142, 27-41. https://doi.org/10.1016/j.coastaleng.2018.08.015

[19] Chiew, Y. M. (1992). Scour protection at bridge piers. Journal of Hydraulic Engineering, 118(9), 1260-1269. https://doi.org/10.1061/(ASCE)0733-9429(1992)118:9(1260)

[20] Ettema, R. (1980). Scour at bridge piers.

[21] Tafarojnoruz, A., Gaudio, R., \& Calomino, F. (2012) Evaluation of Flow-Altering Countermeasures against Bridge Pier Scour. Journal of Hydraulic Engineering, 138(3), 297-305. https://doi.org/10.1061/(ASCE)HY.1943-7900.0000512

[22] Salamatian, S. A. \& Zarrati, A. R. (2019). Reliability study on uncertainty parameters and flood duration on scouring around unprotected and protected bridge piers. ISH Journal of Hydraulic Engineering, 00(00), 1-9. https://doi.org/10.1080/09715010.2019.1570360

[23] Moncada, A. T., Aguirre-Pe, J., Bolívar, J. C., \& Flores, E. J. (2009). Scour protection of circular bridge piers with collars and slots. Journal of Hydraulic Research, 47(1), 119126. https://doi.org/10.3826/jhr.2009.3244

[24] Alabi, P. D. (2006). Time development of local scour at a bridge pier fitted with a collar: University of Saskatchewan.

[25] Jahangirzadeh, A., Basser, H., Akib, S., Karami, H., Naji, S., \& Shamshirband, S. (2014). Experimental and numerical investigation of the effect of different shapes of collars on the reduction of scour around a single bridge pier. PLoS ONE, 9(6). https://doi.org/10.1371/journal.pone.0098592

[26] Chen, S. C., Tfwala, S., Wu, T. Y., Chan, H. C., \& Chou, H. Ter. (2018). A hooked-collar for bridge piers protection: Flow fields and scour. Water (Switzerland), 10(9), 1-12. https://doi.org/10.3390/w10091251

[27] Farooq, R. \& Ghumman, A. R. (2019). Impact assessment of pier shape and modifications on scouring around bridge pier. Water (Switzerland), 11(9), 14-20. https://doi.org/10.3390/w11091761

[28] Farooq, R., Ghumman, A. R., Tariq, M. A. U. R., Ahmad, A., \& K .Z. Jadoon. (2020). Optimal Octagonal Hooked Collar Countermeasure to Reduce Scour Around a Single Bridge Pier. Periodica Polytechnica Civil Engineering, 64(4). https://doi.org/https://doi.org/10.3311/PPci.15966

[29] Ebrahimi, M., Kripakaran, P., Prodanović, D. M., Kahraman, R., Riella, M., Tabor, G., Arthur, S., \& Djordjević, S. (2018). Experimental study on scour at a sharp-nose bridge pier with debris blockage. Journal of Hydraulic Engineering, 144(12), 1-12. https://doi.org/10.1061/(ASCE)HY.1943-7900.0001516

[30] Burkow, M. \& Griebel, M. (2016). A full three dimensional numerical simulation of the sediment transport and the scouring at a rectangular obstacle. Computers and Fluids, 125, 1-10. https://doi.org/10.1016/j.compfluid.2015.10.014

[31] Zhang, Y., Harries, K. A., \& Yuan, W. (2013). Experimental and numerical investigation of the seismic performance of hollow rectangular bridge piers constructed with and without steel fiber reinforced concrete. Engineering Structures, 48, 255-265. https://doi.org/10.1016/j.engstruct.2012.09.040

[32] Zain, H., Khan, Z., Anis, H., \& Farooq, R. (2016). Experimental investigation of stress-strain behavior of CFRP confined Low Strength Concrete ( LSC ) cylinders. CONSTRUCTION \& BUILDING MATERIALS, 104, 208215. https://doi.org/10.1016/j.conbuildmat.2015.12.061

[33] Mashahir, M. B., Zarrati, A. R., \& Mokallaf, E. (2010). Application of riprap and collar to prevent scouring around rectangular bridge piers. Journal of Hydraulic Engineering, 136(3), 183-187. https://doi.org/10.1061/(ASCE)HY.1943-7900.0000145

[34] Zarrati, A. R., Gholami, H., \& Mashahir, M. B. (2004). Application de collier pour contrôler l'affouillement autour des piles de pont rectangulaires. Journal of Hydraulic Research, 42(1), 97-103. https://doi.org/10.1080/00221686.2004.9641188

[35] Zarrati, A. R., Nazahira, M., \& Mashahir, M. B. (2006). Reduction of local scour in the vicinity of bridge pier groups using collars and riprap. Journal of Hydraulic Engineering, 132(2), 154-162 https://doi.org/10.1061/(ASCE)0733-9429(2006)132:2(154)

[36] Melville \& Chiew, Y. (1999). Time scale for local scour at brigde piers. Journal of Hydraulic Engineering, May 2010, 59-65. https://doi.org/10.1061/(ASCE)0733-9429(1999)125:1(59)

[37] Ballio, F., Teruzzi, A., \& Radice, A. (2009). Constriction effects in clear-water scour at abutments. Journal of Hydraulic Engineering, 135(2), 140-145. https://doi.org/10.1061/(ASCE)0733-9429(2009)135:2(140) 
[38] Pagliara, S. \& Carnacina, I. (2010). Temporal scour evolution at bridge piers: Effect of wood debris roughness and porosity. Journal of Hydraulic Research, 48(1), 3-13. https://doi.org/10.1080/00221680903568592

[39] Pagliara, S. \& Carnacina, I. (2011). Influence of wood debris accumulation on bridge pier scour. Journal of Hydraulic Engineering, 137(2), 254-261. https://doi.org/10.1061/(ASCE)HY.1943-7900.0000289

[40] Solaimani, N., Amini, A., Banejad, H., \& TahereiGhazvinei, P. (2017). The effect of pile spacing and arrangement on bed formation and scour hole dimensions in pile groups. International Journal of River Basin Management, 15(2), 219-225. https://doi.org/10.1080/15715124.2016.1274321

\section{Contact information:}

Rashid FAROOQ, Lecturer

Department of Civil Engineering,

International Islamic University,

H-10, Islamabad 44000, Pakistan

E-mail: rashidmeo50@gmail.com

Abdul Razzaq GHUMMAN, Professor,

College of Engineering, Civil Engineering Department,

Qassim University,

Al-Mulida 51431, Saudi Arabia

E-mail: abdul.razzaq@qec.edu.sa

Muhammad Atiq Ur Rehman TARIQ, Adj. Assoc. Professor,

(Corresponding author)

College of Engineering and Science,

Victoria University,

Melbourne VIC 8001, Victoria, Australia

E-mail: atiq.tariq@yahoo.com

Afzal Ahmed, Lecturer

Civil Engineering Department,

University of Engineering and Technology, Taxila

Khanpur Road, Taxila 47080, Punjab, Pakistan

E-mail: afzal.ahmed@uettaxila.edu.pk

\section{Abid LATIF, Professor}

Department of Civil Engineering,

Bahauddin Zakariya University,

Bosan Road, Multan 60000, Punjab, Pakistan

E-mail: abid.latif@bzu.edu.pk

Amjad MASOOD, Scientific Officer

Global Change Impact Studies Centre,

10-MauveArea, G-8/1, Islamabad 44000, Pakistan

E-mail: amjad.masood@gcisc.org.pk 